\title{
Medical Tourism Destination SWOT Analysis: A Case Study of Malaysia, Thailand, Singapore and India
}

\author{
Kee Mun Wong ${ }^{1}$, Peramarajan Velasamy ${ }^{2}$, Tengku Nuraina Tengku Arshad ${ }^{3}$ \\ ${ }^{1}$ School of Business and Accountancy, University of Malaya, 50603 Kuala Lumpur, Malaysia \\ ${ }^{2,3}$ Research and Informatics Department, Malaysia Healthcare Travel Council, 59000 Kuala Lumpur, \\ Malaysia
}

\begin{abstract}
The growth of global medical tourism in the recent years had spurred the interest of many governments to join in the bandwagon, particularly from Asia. Using the SWOT analytical model, this paper provides pertinent comparative analysis of the medical tourism destinations here being Malaysia, Thailand, Singapore and India. Each destination possesses its own value propositions to convince the demands of medical tourists. Malaysia and Thailand have a good mixture of elements (medical, tourism and wellness) to be an excellent medical tourism destination while Singapore and India need further development in some of these elements. Meeting or exceeding the medical tourists' expectations and requirements are the priority of medical tourism destination marketers in ensuring a successful medical tourism industry development.
\end{abstract}

\section{Introduction}

The global flow of patients across borders has changed the patterns of demand and supply of healthcare services over the recent decades [1]. This phenomenon is often described as medical tourism or medical travel. The global medical tourism industry is forecasted to generate a revenue between USD 38 to USD 55 billion [2] annually. While the definition of medical tourism is frequently contested by scholars and medical tourism enthusiasts, Musa et al. (p. 630) defined precisely the phenomenon as "All the activities related to travel and hosting a tourist who stays at least one night at the destination region, for the purpose of maintaining, improving or restoring health through medical intervention" [3]. The medical intervention may cover a wide range of medical services such as dental, cosmetic, fertility and elective procedures. The movement of these services further accelerates the trade liberalisation in health services [1].

Medical tourists are motivated to seek healthcare outside their area of residence by many factors, including cost, time, regulation, medical preferences and availability, quality, leisure tourism and information availability [4]. Hospitality and tourism companies, as well as local governments and destination marketers, are positioning themselves to capture share in the global medical tourism market [5]. In Asia, the main players include Malaysia, Thailand, India and Singapore, where these destinations are expected to control at least $80 \%$ of the Asian market share by 2015 [6]. However, the existing literatures offer little direct comparison between these destinations, thus the competitiveness of each destination remains unclear. Hence, the objective of this paper is to provide a descriptive, yet meaningful comparison of the four medical tourism destinations: Malaysia, Singapore, Thailand and India, through the use of SWOT analysis. 
SWOT analysis is an analytical model that considers and determines the external environmental issues (opportunities and threats) along with internal issues of the examined organisation (strengths and weaknesses), so it allocates the proper strategy on considered situations. To perform the SWOT analysis, we have gathered information and relevant findings from the secondary data published in various research journals, articles, leading newspapers, websites and government reports. The strengths and weaknesses of each medical tourism destination will be first discussed before the opportunities and threats of medical tourism in the region is highlighted.

\section{Malaysia Medical Tourism}

Malaysia has been reputed as one of the preferred medical tourism destinations by its modern private healthcare facilities and highly efficient medical professionals [7]. The nation's 2020 medical tourism target is to hit RM 9.6 billion (approximately USD 3.2 billion) in revenue from 1.9 million foreign patients [8]. In determining to achieve this target, the Malaysian government had initiated the establishment of Malaysia Healthcare Travel Council (MHTC) within the Ministry of Health since 2009. Malaysia received 770,134 foreign patients in 2013, generating USD 216 million (approximately RM 690 million) in revenue [2]. As a Muslim country, Malaysia has all it takes to attract medical tourists from the Middle East and North Africa (MENA) nations whilst currently attracting the highest number of foreign patients from Indonesia [2, 4].

MHTC nurtures active Public-Private Partnership (PPP) through its local and overseas promotional activities (e.g. trade shows, networking sessions, packaging workshops, health talks, familiarisation tours, etc), and by bringing in relevant stakeholders to work together to promote medical tourism through packaging [9]. A dedicated medical tourism website, a call centre, medical tourism concierges and lounges at international airports and overseas representative offices have been established to provide relevant information and value-added services (e.g. hospital appointments, handling medical enquiries, tourism recommendations, etc) to potential medical tourists.

The Malaysian government provides flexible ease of entry for foreign patients entering Malaysia for treatment where visa for medical tourists are extended if needed, from 30 days to 90 days. The facility also allows four accompanying persons to travel with the patient under the same visa conditions [10]. Permits issued by the Commercial Vehicle Licensing Board allow the ministry recognised hospitals to ferry patients to and from the airport and hospital or hotel [11], further enhancing the logistics experience of the medical tourists in Malaysia. Among the popular advanced treatments offered in Malaysia for foreign patients are cardiac procedures, orthopaedic, cancer treatment, fertility treatment, cosmetic surgery and general health screenings. In addition, Malaysia also offers traditional and complimentary medicine (TCM) as alternative medical treatments [4].

Affordable cost, less waiting time, relative political stability, minimal language barrier and various tourism attractions lend Malaysia a distinct comparative advantage [4, 12]. In addition, private healthcare facilities in Malaysia are also driven to attain international accreditation. To date, there are 13 healthcare facilities which had obtained the Joint Commission International (JCI) accreditation [13], where ten of them had also obtained the Malaysian Society for Quality in Health (MSQH) accreditation [14]. While Malaysia is a strong contender in the regional medical tourism scene, it is reported that the country is failing to attract high spending patients as compared to Thailand and Singapore [2]. One contributing factor may be that the Malaysian medical professional's capability may be less convincing to medical tourists as the information about their professionalism is scarce and difficult to locate on the internet.

\section{Thailand Medical Tourism}

International tourists are flocking to Thailand for its unique Thai hospitality, exotic beaches, entertainment opportunities and medical treatments. In fact, the Thai medical tourism started since the $1970 \mathrm{~s}$ [4]. Thailand reported to have received about 2.53 million medical tourists, generating a revenue of between THB 121 to 140 billion (approximately USD 4 to 4.6 billion) in 2012 [15]. Even 
though the statistics are reported to include wellness and spa receipts [2], Thailand is still known as a medical tourism leader globally. While the majority of the medical tourists in Thailand are Japanese, Americans, Britons, Middle Easterns and Australians [15], Chantal and Siripen [16] estimated that about $35 \%$ of the medical tourism receipts is contributed by patients from South East Asian nations. Medical tourists to Thailand can generally enter the country quite easily. Visa on arrival is available for most nationalities. Medical tourists are able to apply for a non-immigrant visa for medical reasons, which grants them 90 days of stay in the country. To lure the medical tourists from the Middle East, Thailand has offered a 90 days visa free stay since 2013 [17].

Besides cosmetic surgery [18], dental treatment is also the most popular treatment among the foreign patients in Thailand [4]. In addition, a number of medical facilities in Thailand offer fringe medical procedures (e.g. gender reassignment) [19] which may not be available elsewhere in the region. Thailand also provides integrated wellness centres and facilities, including the Thai massage, spa, wellness activities and restorative activities [20]. Thai hospitals are among the first in Asia to be internationally accredited. To date, there are 37 hospitals accredited by JCI in Thailand [13], where a majority of them are located in Bangkok [4]. While medical tourists appreciate Thailand's excellent service experience, most of them face language barriers during their stay in Thailand. To overcome the issue, Thai hospitals hire multilingual speaking staffs (e.g. English, Arabic, Japanese, etc). The doctors in Thailand are trained in reference to western training and certification, mostly in the United States or United Kingdom [18]. Similar to other destinations, foreign medical professionals with recognised qualifications are allowed to practice in Thailand, but they are required to pass an examination in Thai language [16]. The stringent requirement sets a barrier for foreign medical professionals to obtain a practicing license from the relevant authorities (e.g. Thai Medical Council, other professional councils).

Historically, Thailand medical tourism is much promoted overseas by independent high-profile private hospitals (e.g. Bumrungrad International Hospital, Bangkok Hospital, Samitivej Hospital). The Tourism Authority of Thailand (TAT) is also currently promoting Thai healthcare services actively by creating worldwide awareness through e-marketing and media campaigns [4]. Familiarisation tours are organised for international media and potential buyers. However, the recent political instability dampened much of its promotional efforts.

\section{Singapore Medical Tourism}

Singapore is a city-state with a small population, hence enabling it to be more decisive in implementing the privatisation of healthcare financing and corporatisation of healthcare provision. While the Singapore government targets to bring in 1 million medical tourists, the statistics reported by the Singapore Tourism Board $(850,000)$ in 2012 has been critically evaluated by medical tourism enthusiasts. IMTJ argued that the numbers are inclusive of accompanying family members and local expatriates, hence, the actual number of medical tourists to Singapore perhaps is only about 200,000, of which $47 \%$ of them are from Indonesia and 12\% are from Malaysia [21].

Similar to Malaysia, the Ministry of Health Singapore had established Singapore Medicine, a government-industry partnership, in 2003. Its objectives are to enhance the medical tourism industry and to strengthen its image as the leading medical hub in Asia [4]. However, the Singaporean government had not indicated its support on medical hub policy explicitly. In fact, the support for medical tourism has become unnoticeable in the recent years, perhaps due to potentially conflicting goals of trade and health policies that may spark controversial public opinions [16].

Singapore's medical tourism strategies are built on its high quality medical care, trustworthy and internationally accredited hospitals [4]. With 21 JCI accredited hospitals [13], Singapore endeavours to provide top notch healthcare delivery system and facilities to its citizens, hence, possessing some of the most advanced diagnosis equipment available in the market [22]. English is widely spoken, clean and safe environment and a stable political scene attract tourists to Singapore [23]. In Singapore, foreign doctors made up more than half of the 836 new doctors in the year 2011 and its stated that 
more than one in three doctors in the public sector is a foreigner [24]. While this may benefit the international patient market, over reliance on foreign doctors may be a threat to the country when the doctors return to their home countries or shift elsewhere due to social and/or economic reasons.

Singapore's positioning on high end complex quality healthcare [25] eventually weakens its price competitiveness in the region (refer Table 1). Besides, while most medical tourism destinations actively promote and position itself in the much contested medical tourism market, Singapore is somehow lacking in its efforts to further expand its medical tourism industry [25]. In addition, the shortage of beds in public hospitals continues to be a problem for Singapore [24] which causes its citizens to question the emphasis of the government on medical tourism over public health equity.

\section{India Medical Tourism}

India has emerged as one of the world's most cost efficient and fastest growing medical tourism destinations today [26]. The uniqueness of India is its ability to offer holistic medical services such as unani, yoga, meditation, ayurveda, and homeopathic treatments $[4,26]$. Despite the advantage of having low medical costs (refer Table 1), the Indian government is taking a different approach in promoting its medical tourism industry by highlighting its wellness elements.

The Indian Ministry of Tourism is actively promoting medical tourism through overseas roadshows where market development assistance (MDA) is provided to medical and wellness tourism service providers to encourage overseas promotion. The government had introduced medical visa to govern medical tourism [26]. In order to further expand the healthcare system and enhance its quality, the government also actively provides incentives and giving special approvals to foreign firms for direct investments. Vice versa, some of its large hospital groups (i.e. Apollo Hospitals, Fortis Healthcare) are expanding overseas, creating a strong global brand name and building referral opportunities. Among the most popular sought after treatments by the medical tourists in India are cardiac surgery, orthopaedic, dental care, cosmetic surgeries, organ transplant and surrogacy [27], where the latter two may not be easily available in other destinations. The Indian Ministry of Tourism reported that 171,021 foreign tourists visited India for medical purpose in 2012, an increase of about $23 \%$ from the previous year. Most of the medical tourists are from South Asia, Africa and Middle East [28]. While a majority of them prefer India due to the low cost factor, the destination also offers less waiting time in the hospital, personalised services, medical specialisation and highly trained doctors $[4,29]$. As a world-renowned medical study destination, India produces more than 30,000 medical graduates annually [4]. India has 21 JCI accredited hospitals [13] where the majority of them are situated within the cities of New Delhi and Mumbai [4].

Despite the growth of medical tourism, the infrastructure system (e.g. flight connectivity, roads, public transport) and general hygiene conditions in India are still lacking far behind by the Western standards $[30,31]$. Foreign patients are reported to have less trust of Indian hospitals, particularly when there is a lack of uniform pricing policies and standards across hospitals [30]. The recent rape cases of foreign tourists and increasing crime rates in India further tarnished its tourism destination image [32]. The negative image may cause medical tourists to practice extra cautions before deciding to seek treatment in India.

\section{Opportunities and Threats of Medical Tourism in the Region}

The global healthcare spending is expected to escalate by 5.3\% from 2014 to 2017 and account for an average of above $10 \%$ of gross domestic product (GDP) [33]. Healthcare is the second highest government spending among the developed nations (i.e. 17.4\% of GDP in the United States (US), $10.7 \%$ of GDP in Western Europe) [33]. The rising medical costs eventually drive the people from the developed nations (e.g. the US, United Kingdom, Australia) to seek treatment overseas, particularly for treatments which are not covered by their insurance (e.g. eye, dental, cosmetic and fertility 
treatment). Although the current ex-change rate of Asian currencies is least favourable as compared to the late $90 \mathrm{~s}$, a comparison of a few popular treatment costs between the US and the Asian medical tourism destinations still indicates a cost savings of between $40 \%$ to $95 \%$ (refer Table 1 ). The medical tourism insurance policy offered by insurance firms in the US and Australia further ensure medical tourists have peace of mind when seeking treatment overseas [34, 35].

Treatments that require long waiting periods (e.g. open heart surgery, joint replacement, cancer treatment) or treatments that are simply not available in their home countries (e.g. surrogacy, organ transplant, stem cell therapy) is also a motivating factor for them to go overseas [4]. The rising role of medical travel facilitators and second home retirement tourism in Asia further support the surge of cross-border healthcare services demand [36, 37]. These factors create opportunities for the Asian medical tourism destinations to take advantage of. In the perspective of healthcare excellence in medical tourism, Malaysia and India seem to excel better as several of their healthcare facilities had won international medical tourism awards introduced by the MTQUA and IMTJ recently [38, 39].

Table 1. Average Medical Cost Comparison (in USD).

\begin{tabular}{|c|c|c|c|c|c|}
\hline Treatment & United States & Malaysia & Thailand & Singapore & India \\
\hline Heart Bypass (CABG) & 136,000 & 14,000 & 13,000 & 23,000 & 7,000 \\
\hline Angioplasty & 57,000 & 8,750 & 3,800 & 27,750 & 3,300 \\
\hline Knee Replacement & 45,000 & 10,900 & 11,400 & 16,700 & 6,800 \\
\hline Gastric Bypass & 33,000 & 8,600 & 16,700 & 20,000 & 5,500 \\
\hline
\end{tabular}

Source: Authors, August 2014, compiled from healthcare providers, medical tourism providers and online resources

Postoperative complications and aftercare at the patient's country of residence remain a major deterrent of medical tourism [40, 41]. Besides, the recent political instability and surrogacy scandal in Thailand, the aviation disasters in Malaysia and the rising crime rate in India further impact the tourism sector of these countries. While it is a threat to these countries, it is also an opportunity for others in luring medical tourists from these competing destinations. The imposing of Indian medical visa and the lack of Singapore government's interest in further promoting medical tourism globally is also seen as an opportunity by other regional players. As the medical tourism industry continues to develop in Asia, several ethical issues were raised. Illegal organ trades have been reported in India, while gender reassignment surgery is becoming a norm in Thailand [4]. From a bioethical point of principle, under certain conditions, these surgeries and treatments are morally non-acceptable and cannot be categorised $[42,43]$.

While the opportunities and threats can be generalised to all destinations, certain threats can be destination specific. For example, the destination's image is affected due to political instability (in Thailand), aviation disasters (in Malaysia), lack of government focus on medical tourism (in Singapore) and increasing crime rate (in India). The comparative SWOT analysis of the medical tourism destinations is summarised in Figure 1. 


\section{Conclusion}

Medical tourism destinations are developed mainly for economic reasons. Different destination offers unique value propositions in attracting this lucrative and growing market. Malaysia offers a value for money experience while Singapore highlights their sophisticated medical technology. India uniquely positions itself with the holistic medical services and Thailand's hospitality services are no match to its competitors in the region.

The SWOT analysis suggests that Malaysia needs further value creations in niche treatment, advanced technologies and medical excellence in order to attract high spending patients. Thailand, being the market leader, requires strong campaigns to regain its positive destination image. India should improve its infrastructure, hygienic environment and security conditions to complement its low cost advantage. Medical tourism destination marketers should put more emphasis on the integration between medical, tourism and wellness services in order to excel in medical tourism holistically. Both Malaysia and Thailand probably have all these elements and Thailand has an advantage of being well recognised internationally for decades. India needs to develop more attractive tourism products while Singapore needs to further enhance its offerings in both wellness and tourism services.

Despite limited information, this paper provides useful insights to both the academics and practitioners on the competitiveness of Asian medical tourism destinations. While low cost is one of the Asian destination's selling points, the recent currency fluctuations in the global market depreciate their cost advantage. Besides, the rise of the European, Middle Eastern and South American medical tourism destinations in recent years post direct threat to Asian destinations in luring high spending western medical tourists. Thus, the ability of Asian destinations to meet or exceed medical tourists' expectations and requirements is essential in ensuring the sustainability of its medical tourism development.

\section{References}

1. N. Lunt, R. Smith, M. Exworthy, S.T. Green, D. Horsfall, R. Mannion, Medical Tourism: Treatments, Markets and Health System Implications: A Scoping Review, 1-55 (OECD, 2011)

2. T. Leong, Malaysia tries to parlay appeal to Muslim visitors into medical tourism push, http://www.reuters.com/article/2014/07/29/us-malaysia-medical-idUSKBN0FY2AT20140729 (2014)

3. G. Musa, D..R. Doshi, K.M. Wong, T. Thirumoorthy, J Travel Tour Mark 29, 629-646 (2012)

4. K.M. Wong, G. Musa, Medical Tourism: The Ethics, Regulation and Marketing of Health Mobility, 167-186 (2012)

5. K. Wendt, UNLV Theses/Dissertations/Professional Papers/Capstones. Paper 1483, (2012)

6. Renub Research, Asia Medical Tourism Analysis and Forecast to 2015, http://www.reuters.com/article/2012/10/23/idUS80088+23-Oct-2012+BW20121023 (2012)

7. B.J. Shah, An Insight into Malaysia's Medical Tourism Industry from a New Entrant Perspective, http://www.valuenetworksandcollaboration.com/images/bhavinshahmbamedicaltourismindustrymalaysia.pdf (2008)

8. Pemandu, Creating wealth through excellence in healthcare, http://www.moh.gov.my/images/gallery/ETP/NKEA\%20Penjagaan\%20Kesihatan.pdf (2010)

9. Health and Care Bureau, Malaysia was once known as the "Hidden Jewel in Healthcare", http://healthandcare.in/malaysia-was-once-known-as-the-hidden-jewel-in-healthcare/ (2013)

10. M.K. Yuen, Malaysia competes in medical tourism, http://www.ttrweekly.com/site/2013/06/malaysia-competes-in-medical-tourism/_(2009a)

11. M.K. Yuen, Malaysia's visa change is a boost for healthcare tourism, http://www.eturbonews.com/13394/malaysias-visa-change-boost-healthcare-tourism (2009b)

12. IMTJ, MALAYSIA: Malaysia can be medical tourism hub, http://www.imtj.com/news/?EntryId82=152011 (2009) 
13. JCI, JCI-Accredited Organizations, http://www.jointcommissioninternational.org/about-jci/jciaccredited-organizations/ (2013)

14. MSQH, List of Hospital With Current Accreditation Status, http://www.msqh.com.my/msqh/ctmenu-item-19/ct-menu-item-21/ct-menu-item-33 (2014)

15. MyMEDHoliday, Thailand's Medical Tourism Statistics: a Look at the International Patient Numbers, http://www.mymedholiday.com/blog/2013/10/793/thailands-medical-tourism-statisticsa-look-at-the-international-patient-numbers/ (2013)

16. H. Chantal, S. Siripen, Medical Tourism in Malaysia, Singapore and Thailand, https://editorialexpress.com/cgibin/conference/download.cgi?db_name=SERC2013\&paper_id=230 (2014)

17. MyMEDHoliday, Thailand Visa Requirement for Medical Tourists, http://www.mymedholiday.com/country/thailand/article/177/thailand-visa-requirements-formedical-tourists (2014)

18. A. Wilson, Body Soc 17, 121-137 (2011)

19. I. Olson, Fringe Medical Practices in Thailand, http://www.thailawforum.com/laws/medicalpractices-thailand-stem-cell-cloning-cancer-sex-change.pdf (2010)

20. Thailandmedicaltourismcluster.org, What Makes Thailand A Prime Medical Destination, http://www.thailandmedicaltourismcluster.org/AboutMedicalTourism/WhyThailandNo1inMedica IDestination/WhatmakesThailandaprimemedicaldestination.aspx (2010)

21. IMTJ, SINGAPORE: Singapore medical tourism is recovering, http://www.imtj.com/news/?entryid82=413890 (2013)

22. AsiaOneYourHealth, Singapore: At the forefront of medical tourism, http://yourhealth.asiaone.com/content/singapore-forefront-medical-tourism (2014)

23. B.S.A. Yeoh, E.S. Tan, J. Wang, T. Wong, Tourism Management Policy (World Scientific, 2002)

24. Singapore General Hospital, Shortage of hospital beds, so some ops delayed, http://www.sgh.com.sg/about-us/newsroom/News-Articles-

Reports/Pages/Shortageofhospitalbeds,sosomeopsdelayed.aspx (2013)

25. J. Rerkrujipimol, I. Assenov, J Tour Hosp Culinary Arts 3, 95-105 (2011)

26. L. Singh, African J Hosp Tour Lei 3, 1-11 (2014)

27. N. Swamy, The Preferred Destination, http://indiatoday.intoday.in/story/world-class-treatmentand-cheaper-deals-medical-assistance/1/347252.html (2014)

28. Ministry of Tourism India, India Tourism Statistics 2012, (Market Research Division, 2013)

29. Knowledge@Wharton, Will medical tourism be India's next big industry, http://knowledge.wharton.upenn.edu/article/healthy-business-will-medical-tourism-be-indiasnext-big-industry/ (2011)

30. S.K. Dawn, S. Pal, Int J Multidiscip Res 1, 185-202 (2011)

31. L.L. Gan, H. Song, A SWOT Analysis of Medical Tourism: India and South Korea, http://papers.ssrn.com/sol3/papers.cfm?abstract_id=2194856 (2012)

32. P. Rana, Attacks on women rattle travelers to India, http://online.wsj.com/news/articles/SB10001424052702304244904579278050017041212 (2014)

33. The Economist Intelligence Unit (EIU), World Healthcare Outlook, (2014)

34. S. Parnell. Health fund NIB to offer medical tourism, http://www.theaustralian.com.au/news/health-science/nib-health-fund-to-offer-medicaltourism/story-e6frg8y6-1226747206131 (2013)

35. MyMEDHoliday, Medical Tourism Insurance Companies, http://www.mymedholiday.com/providers/170/medical-tourism-insurance-companies (2014).

36. M. Ormond, R. Holliday, M. Jones, Navigating international medical travel: A three-country study of medical travel facilitators sending patients to Malaysia (ISA Annual Conference, Yokohama, 2014)

37. K.M. Wong, G. Musa, Tourism Manage 40, 141-154 (2014) 
38. B. Neild, First medical tourism awards tout top treatment trips, http://edition.cnn.com/2014/04/22/travel/medical-tourism-awards/ (2014)

39. MTQUA, MTQUA 2013 World's Best Hospitals for Medical Tourists, http://www.mtqua.org/providers/top-10-worlds-best-hospitals-for-medical-tourists-list/ (2013)

40. M.D. Horowitz, J.A. Rosensweig, C.A. Jones, Medscape Gen Med 9, 33 (2007)

41. Deloitte, Medical Tourism - Consumers in Search of Value, 1-30 (Deloitte Center for Health Solutions, 2008)

42. M.C. Hume, Res Cogitans 2, 37-48 (2011)

43. B. Paul, M. Valapour, D. Bartels, A. Abbott-Penny, J. Kahn, Ethics of Organ Transplantation, 148 (Center for Bioethics, 2004) 